\title{
Social relationships of wild juvenile Asian Elephants Elephas maximus in the Udawalawa National Park, Sri Lanka
}

\author{
Deepani Jayantha ${ }^{1}$, P.N. Dayawansa ${ }^{2}$, U.K.G.K. Padmalal ${ }^{3}$ \& W.D. Ratnasooriya ${ }^{2}$ \\ 1,2 Department of Zoology, University of Colombo, Colombo 03, Sri Lanka \\ ${ }^{3}$ Department of Zoology, The Open University of Sri Lanka, Colombo, Sri Lanka \\ Email: ${ }^{1}$ deepanij@yahoo.com
}

Date of online publication 26 April 2009 ISSN 0974-7907 (online) | 0974-7893 (print)

Editor: L.A.K. Singh

Manuscript details:

Ms \# 01831

Received 31 July 2007

Final received 13 February 2008

Finally accepted 16 June 2008

Citation: Jayantha, D., P.N. Dayawansa, U.K.G.K. Padmalal \& W.D. Ratnasooriya (2009). Social Relationships of Wild Juvenile Asian Elephants Elephas maximus in the Udawalawa National Park, Sri Lanka. Journal of Threatened Taxa 1(4): 211-214.

Copyright: () Deepani Jayantha, P.N. Dayawansa, U.K.G.K. Padmalal \& W.D. Ratnasooriya 2009. Creative Commons Attribution 3.0 Unported License. JoTT allows unrestricted use of this article in any medium for non-profit purposes, reproduction and distribution by providing adequate credit to the authors and the source of publication.

Author Details: See end of article

Author Contribution: The first author designed and conducted the current study while the other authors supervised her research work and scientific writing.

Acknowledgements: The authors extend their sincere gratitude to the Department of Wildlife Conservation, specially to the staff, Udawalawa National Park. The Born Free Foundation, UK is acknowledged for the financial support.

\begin{abstract}
Social relationships of juvenile wild elephants (3-6 years old) in the Udawalawa National Park were studied. Focal animal sampling was employed to quantify behaviour of juveniles encountered on 450 different occasions. Nearest neighbour (NN) and nearest neighbour distance (NND) were considered for proximity analysis and the social relationships of focal animals. Adult females and juveniles were the NN of the study group during $50.8 \%$ and $37.6 \%$ of the total observed time respectively. The mean NND was $1.62 \mathrm{~m}(\mathrm{SD} \pm 2.8)$, and it was less than $5 \mathrm{~m} 98 \%$ of the time while $33 \%$ of the time the study group was touching $(N N D<1 \mathrm{~m})$ the NN. There was a significant difference between NND categories $(p<0.05)$. Eighty percent of the NN infants stayed at a touching distance and were cared or allo-mothered by the juveniles under discussion. Time allocated for different behaviour patterns by the study group varied with the NN. When the study animals were accompanied by age-mates, they spent $17 \%$ of time in social playing and another $3 \%$ in non-play social contacts, but only $1 \%$ in each behaviour pattern when the adult females were in close proximity. Maximum social contacts were observed between study animals and infants. The findings suggest that juvenile elephants associate more frequently with adult females and near-age mates while they show social relationships in a varying degree with different associates. Play and social contacts of juveniles with conspecifics, especially with peers, provides opportunity to develop skills and social confidence necessary in adulthood.
\end{abstract}

Keywords: Juvenile elephants, social relationships, Sri Lanka, Udawalawa National Park.

\section{INTRODUCTION}

Social interactions and relationships among elephants are maintained by communication, interactive behaviour and proximity (Garai 1997; Sukumar 2003). Young elephants spend several years in physical and behavioural development, and the diverse behaviours exhibited by adult elephants reflect this long history of social interaction and learning (Sukumar 2003). Interactions of juveniles with their associates provide opportunities for learning and improving cognitive and motor skills (Sukumar 1994). Social play allows juvenile elephants to understand coping strategies, practice their abilities and learn their position in the hierarchy (especially males), which all contribute to a long-term learning process (Garai \& Kurt 2006). Continual contacts between mother and calf reassure the psychological well being of the growing animal (Sukumar 1994; 2003). Female juveniles are interested in younger siblings and demonstrate allomothering behaviour frequently (Moss 1988). This behaviour is necessary for the growing female to acquire mothering skills that contribute to adult life (Morris 1990), as experienced females tend to have high offspring survival rates (Garai \& Kurt 2006).

Quantified data on relationships formed by a focal animal can help to determine its well-being with respect to the way the individual gets along with others and how others react to him (Russell 1973). In this context, the present study was conducted in the Udawalawa National Park, Sri Lanka with the objective of describing social relationships of juvenile wild elephants. It is expected that the baseline information could be used in assessing adaptability and level of acceptance of rehabilitated juveniles which are integrated with the wild population in the same park.

\section{Methods}

Study area

The Udawalawa National Park (UNP) is in the intermediate zones of southern Sri Lanka $\left(06^{\circ} 25^{\prime}-06^{\circ} 35^{\prime} \mathrm{N} \& 80^{\circ} 45^{\prime}-81^{\circ} 00^{\prime} \mathrm{E}\right)$ and currently has $30,821 \mathrm{ha}\left(308 \mathrm{~km}^{2}\right)$ of scrublands, grasslands and dry-mixed evergreen forests as dominating vegetations. Extensive areas of Panicum maximum dominated grasslands, which have resulted from shifting cultivation practiced before constitution of the national park in 1972 (EML consultant 2006), are heavily utilized by the elephants along with seasonal grasslands 
adjoining the Udawalawa Reservoir. The authors believe that UNP harbors a healthy breeding population of elephants exceeding 500 individuals (Jayantha \& Dayawansa 2006).

\section{Study group}

Juvenile animals of estimated age 3-6 years old were observed in the study. This age group is partially parallel to 'young juveniles' as explained by Santiapillai in 2004. Based on Sukumar (1994) the elephant population in the UNP was categorized into eight different groups in the field level (Fig. $1)$.

1. INF: Infants - animals of shoulder height up to the level of ventral abdomen of an average adult female; approximately day $1-1 \frac{1}{2}$ years old.

2. JV I: Juveniles (Class I) - shoulder height varying between ventral abdomen and neck level of the adult female; approximately $1 \frac{1}{2}-3$ years old.

3. JV II: Juveniles (Class II) - shoulder height varying between neck and eye level of the adult female; approximately 3-6 years old. This is the study group and referred to the focal animals in the text.

4. JV III: Juveniles (Class III) - shoulder height varying between eye and dorsal canthus of ear opening of the adult female; approximately 6-10 years old. (Juvenile males would be slightly taller than juvenile females of the same age.)

5. SAF: Sub adult females - shoulder height varying between dorsal canthus of ear opening and shoulder level of the adult female; approximately 10-12 years old.

6. SAM: Sub adult males - shoulder height is just below or as the same that of the adult female; approximately 10-15 years old.

7. AF: Adult females - grown females pregnant, lactating or weaned; appearance of mammae (whether suckled or not) is considered.

8. AM : Adult males - grown males of shoulder height more than that of an average adult female; approximate age more than 15-20 years.

\section{Study protocol}

The selected animal group was observed in UNP from April 2004 to March 2005. Focal animal sampling and continuous recording (Martin \& Bateson 1993) was conducted for 14 days per month to quantify behaviour of the juveniles encountered on 450 different occasions. Total sampling time was 4500 minutes. Hides and distant observation (using $8 \times 40$ binoculars) were employed to minimize observer effect on the subjects. The nearest neighbour ( $\mathrm{NN}$ ) of the focal animal and distance to the nearest neighbour (DNN) (Garai 1997) were recorded together with the different behaviours expressed. Data analyzed irrespective of the sex and descriptive statistics were used to describe the findings.

\section{Results}

1. Nearest Neighbour (NN) frequency: Juveniles of age 3-6 years old were observed approximately half of the time $(50.7 \%)$ with adult females, possibly their mothers. They spent $37.6 \%$ of the time collectively with juveniles showing a preference towards age-mates. Sub adult females and sub adult males were the $\mathrm{NNs}$ of the focal group nearly at the same frequencies, $4.2 \%$ and $4.0 \%$ respectively. Infants were seen near

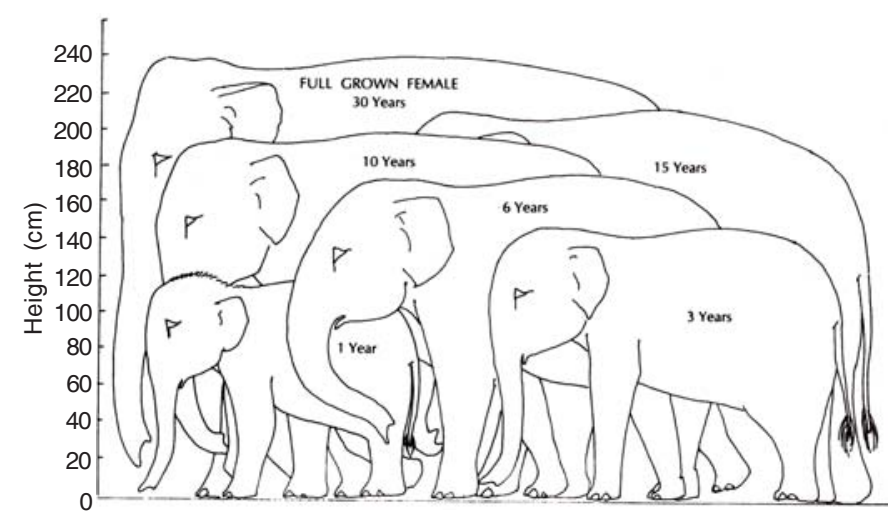

Figure 1. Relative height of young female elephants in relation to full grown female (after Sukumar 1994)

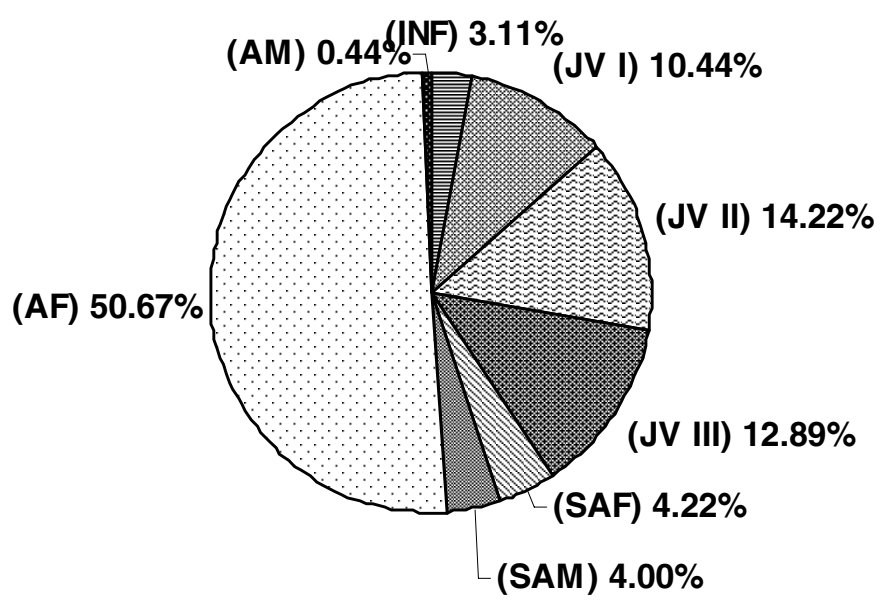

Figure 2. Frequencies of NNs of juvenile elephants as a proportion of total encounters (Symbols as in text)

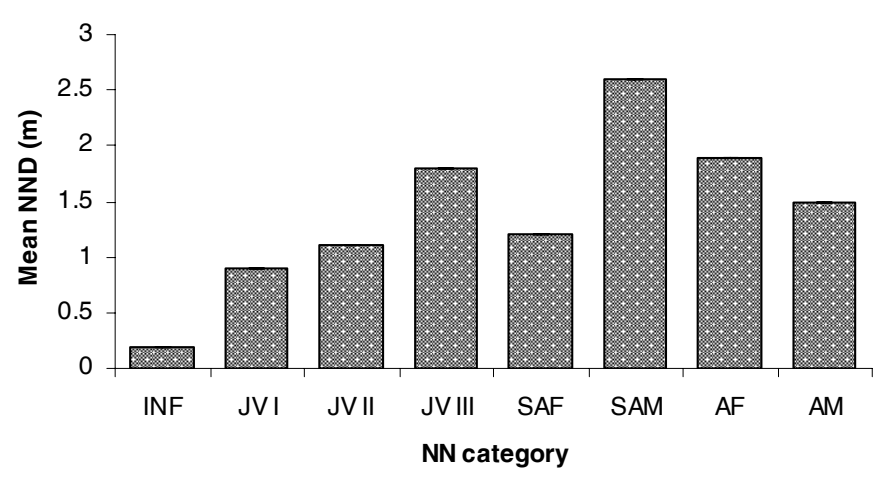

Figure 3. Mean NND between focal juvenile elephants and different NNs. (Symbols as in text)

to the study group $3.1 \%$ of the total occasions and it was the adult males that made least NN frequency (0.4\%) (Fig. 2).

2. Nearest Neighbour Distance (NND): Mean NND was $1.62 \mathrm{~m}$ ( $\mathrm{SD} \pm 2.8$, range $0-40 \mathrm{~m}$ ). Mean NND for different $\mathrm{NN}$ categories varied significantly (ANOVA, one-way, $\mathrm{p}<0.05$ ). A clear pattern of mean NND was evident when young animals ( $<10$ years old) considered as the $\mathrm{NN}$ collectively; with increasing age (and body size) NND increased (Fig. 3).

Overall, the $\mathrm{NN}$ was within $5 \mathrm{~m}$ away from the focal animals $98 \%$ of the time, and during $33 \%$ of the encounters they were 


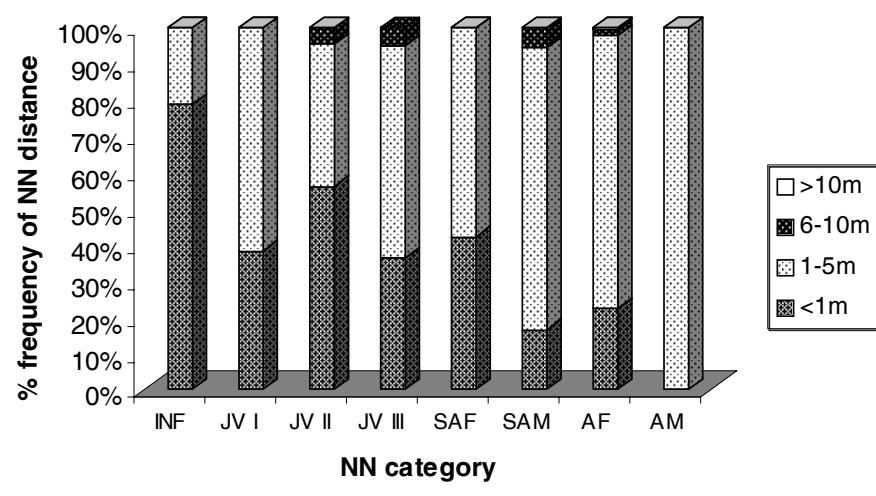

Figure 4. Percentage frequency of NND in relation to NN categories (Symbols as in text)

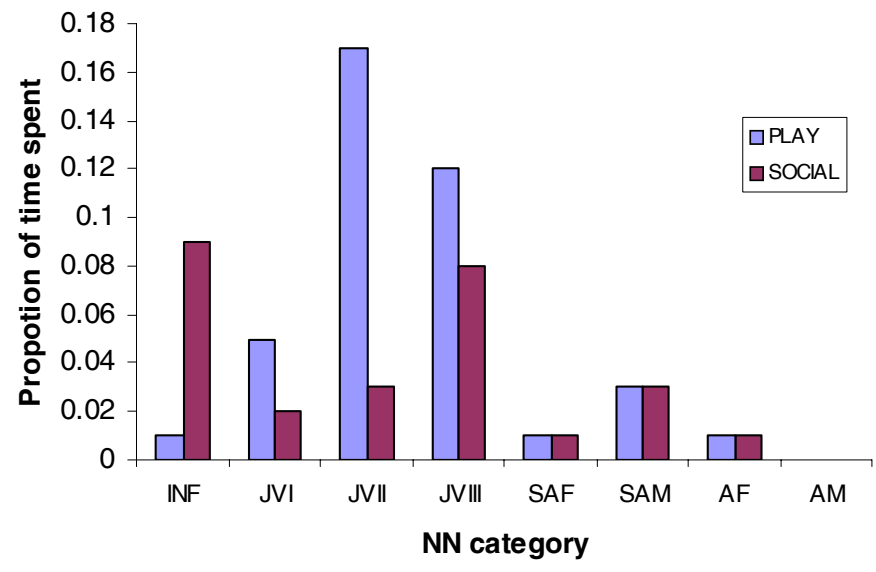

Figure 5. Proportions of time spent for social play (Play) and non-play social (Social) contacts by the juvenile elephants with each NN category. (Symbols as in text)

touching the $\mathrm{NN}(\mathrm{NND}<1 \mathrm{~m})$. Eighty percent of the total juvenile-infant associations was close proximity $(\mathrm{NND}<1 \mathrm{~m})$. The study group stayed between 5-10m away from the $\mathrm{NN}$ in less than $2 \%$ of observations, and were very rarely at a distance $>10 \mathrm{~m}$ (Fig. 4).

3. Social behaviours in relation to the Nearest Neighbour: The juveniles under discussion expressed different behaviour patterns; only three patterns were directly related to the current social context. They are social play, non-play social contacts and agonistic interactions. Since only four agonistic behaviours were recorded (hit by adult females twice, hit a sub adult female and a Class II juvenile) for the total of 450 encounters, agonistic behavior is not considered in the discussion.

Elements which were recorded under social play and nonplay social contacts are presented in Table 1. Time allocated for each pattern was calculated as a proportion of the total time the focal animals spent in association of different $\mathrm{NN}$ categories (Fig. 5).

Social play was generally high when the study group had juveniles as the $\mathrm{NN}$; the most time was spent with age mates $(17 \%)$. Non-play social contacts were highest between infants and the study animals. Focal animals spent relatively little time in association with sub adult and adult females for social play and non-play social contacts. They had no play or social contacts with adult males. The interactions with sub adult males
Table 1. Elements of behaviours expressed by the juvenile elephants related to the current study.

\begin{tabular}{|c|c|}
\hline Element & Description \\
\hline $\begin{array}{l}\text { Social play } \\
\text { Play chasing } \\
\text { Play charging } \\
\text { Play hitting } \\
\text { Play trunk twist } \\
\text { Play tusking } \\
\text { Play mounting } \\
\text { Play pushing } \\
\text { Pressing } \\
\text { Trunk over }\end{array}$ & $\begin{array}{l}\text { Run after another animal; inoffensive } \\
\text { Rush towards a partner; inoffensive } \\
\text { Stroke with trunk; inoffensive } \\
\text { Wrapped trunks; inoffensive } \\
\text { Stroke with tusks/tushes; inoffensive } \\
\text { Climb up on partner's back; not sexual } \\
\text { Press partner hardly; inoffensive } \\
\text { Gentle push on partner with head or body; inoffensive } \\
\text { Place trunk over partner }\end{array}$ \\
\hline $\begin{array}{l}\text { Non-play social } \\
\text { Touching } \\
\text { Testing }\end{array}$ & $\begin{array}{l}\text { tacts } \\
\text { Touch and feel a partner with trunk } \\
\text { Smell organs of the partner with trunk }\end{array}$ \\
\hline
\end{tabular}

probably have brought about by the juvenile males. The findings are summarized in the Table 2 .

\section{Discussion}

Juvenile elephants spend the highest proportion of time with the adult females, particularly with their mothers and other adult females of the group (Kurt 2002; Lee 1986; McKay 1973; Sukumar 2003). This fact is further supported by the current study. The association must have significance in the social context beyond the mere biological need for suckling as only six observations were made of suckling focal animals, which were near their weaning age during the study period. The high associations between juveniles (2-10 years old) can be described as 'peer socialization', during which most of the juvenile contacts are made with members of the group other than the mother (Moss 1998; Sukumar 2003). It was observed during the study that juveniles of 2-10 years old formed social groups within the cow-calf groups. The study group also accompanied infants, parallel to Lee's (1987) and Moss's (1988) observations of how juvenile females accompany younger siblings. The term 'allo-mothering' (Santiapillai 2004) describes this association as the juvenile or adolescent females comforting, assisting and protecting their younger siblings in the family. Nursing infants stay with their mothers $100 \%$ of the time according to Gunawardene et al. (2004) in Sri Lanka; it is worthwhile to note the possible overlapping of age and size categories of the two studies.

The focal animals stayed in close proximity with their nearest neighbours. However, the mean nearest neighbour distance for different age and size categories varied showing a particular trend among growing animals. From infant to sub adult age or size, the distance increased gradually, probably because young elephants move away from their nearest neighbours with increasing age to explore their environment (Gunawardene et al. 2004; Sukumar 2003). According to Garai (1997), close proximity of juvenile elephants is a sign of less social confidence (i.e. the juveniles are not comfortable being solitary).

Playing is an important aspect of learning in juvenile elephants. Playing in mammals can be acrobatic (primates), exploratory (felids) or social (Morris 1990). Social play in juvenile elephants allows them to recognize kin and to form of social bonds useful in the future (Sukumar 2003). Juveniles of 
Table 2. Percentage NN frequency, mean NND, percentage time spent for social play and non play social contacts regarding each NN category. ( $n=$ number of individuals). (Symbols as in text)

\begin{tabular}{lcccc}
\hline NN category & $\begin{array}{c}\text { \% NN } \\
\text { frequency }\end{array}$ & $\begin{array}{c}\text { Mean NN } \\
\text { distance }(\mathbf{m})\end{array}$ & $\begin{array}{c}\text { \% time spent } \\
\text { for social play }\end{array}$ & $\begin{array}{c}\text { \% time spent for } \\
\text { non- play social contacts }\end{array}$ \\
\hline INF $(n=14)$ & 3.1 & 0.2 & 1 & 9 \\
JV I $(n=47)$ & 10.5 & 0.9 & 5 & 2 \\
JV II $(n=64)$ & 14.2 & 1.1 & 17 & 3 \\
JV III $(n=58)$ & 12.9 & 1.8 & 12 & 8 \\
SAF $(n=19)$ & 4.2 & 1.2 & 1 & 1 \\
SAM $(n=18)$ & 4.0 & 2.6 & 3 & 3 \\
AF $(n=228)$ & 50.7 & 1.9 & 0 & 1 \\
AM $(n=2)$ & 0.4 & 1.2 & 0 & 0 \\
\hline
\end{tabular}

3-6 years old spent most of their play time with near-age animals. The same observations have been made on Amboseli elephants (Lee 1987). With infants, they allocated more time for nonplay social contacts which indicates possible allo-mothering. Focal animals had less social interactions with sub adults and adult females compared to young animals.

The focal juveniles associated least with adult male elephants. In cow-calf groups, adult males are seen occasionally. However, the interactions between growing animals and adult males become important during their adulthood. For example, juvenile male African elephants that grew up without the presence of adult bulls, became delinquent and showed aberrant behaviour such as intra and inter specific aggression in South Africa (Slotow et al. 2000; Slotow \& van Dyk 2001), suggesting that normal behaviours are learnt through modeling.

\section{Conclusions}

Close proximity of juvenile elephants of 3-6 years old with the adult females and near-age juveniles coincides with social interactions. The majority of the time they stayed within $5 \mathrm{~m}$ distance from their nearest neighbours, showing less social confidence to do so. Social play and non-play social contacts were the primary behaviour patterns of interest regarding social relationships. The first pattern was frequent among nearage juveniles and the second was predominant between infants and juveniles. Young animals form juvenile groups of nearage members and young juveniles sometime play allomothering role for infants. Play and other social interactions experience by juvenile elephants would help in acquiring social skills expressed in later life.

\section{REFERENCE}

Environment Management Limited Consultant (2006). Report of the habitat mapping of Udawalawa National Park to the Department of Wildlife Conservation, Sri Lanka. Environment Management Limited Consultant, Colombo 4, Sri Lanka, 23pp.

Garai, M.E. (1997). The development of social behaviour in translocated juvenile African elephants, Loxodonta africana (Blumenbach). Ph.D. Dissertation, University of Pretoria.

Garai, M.E. \& F. Kurt (2006). The Importance of Socialisation to the Well Being of Elephants. Zeitschrift des Kölner Zoo. Heft 2: 49.

Gunawardene, M.D., L.K.A. Jayasinghe, H.K. Janaka, D.K. Weerakoon, E. Wickramanayake \& P. Fernando (2004). Social Organization of Elephants in southern Sri Lanka. In: Jayawardene, J. (Ed.). Endangered Elephants; Past, Present \& Future. Biodiversity \& Elephant Conservation Trust, 66pp.

Jayantha, D. \& P.N. Dayawansa (Eds.) (2006). Airavana. Serial Publication of the of the project ELEMONI-SL; Juvenile elephant monitoring project, Udawalawa National Park. University of
Colombo \& Department of Wildlife Conservation, Sri Lanka, 1(1): 5 .

Kurt, F. (2002). Physical and social development in captive-born and orphaned Asian elephants of the Pinnawela Elephant Orphanage (Sri Lanka). In: Proceedings of Workshop on Captive Elephant Management. Trichur, India.

Lee, P.C. (1986). Early social development among African elephant calves. National Geographic Research 2: 388-4.1.

Lee, P.C. (1987). Allomothering among African Elephants. Animal Behaviour 35: 278-291

Martin, P. \& P. Bateson (1993). Measuring Behaviour: An introductory guide. $2^{\text {nd }}$ Edition. Cambridge University Press, UK.

McKay, G.M. (1973). Behaviour and Ecology of the Asiatic Elephants in Southeastern Ceylon. Smithsonian Contribution to Zoology 125: 69.

Morris, D. (1990). Animal Watching. Arrow Books Limited. 230pp.

Moss, C. (1988). Elephant Memories; Thirteen years in the life of an elephant family. The University of Chicago Press. 145-174pp.

Russell, R.D. (1973). Social Health: An attempt to clarify this dimension of well-being. International Journal of Health Education 16: 74-75.

Slowtow, R., G. van Dyk, J. Poole, B. Page \& A. Klocke (2000). Older bull elephants control young males. Nature 408: 425-426.

Slowtow, R. \& G. van Dyk (2001). Role of delinquent young 'orphan' male elephants in high mortality of white rhinoceros in Pilanesberg National Park, South Africa. Koedoe 44/ 1: 85-94.

Santiapillai, C. (Ed.) (2004). Gajah - Journal of the Asian Elephant Specialist Group 23: 16.

Sukumar, R. (2003). The Living Elephant; Evolutionary Ecology, Behaviour and Conservation. Oxford University Pres, New York, 125-190pp.

Sukumar, R. (1994). Elephant Days and Nights; Ten years with the Indian Elephant. Oxford University Press, New Delhi, 86-109pp.

Author Details: DeEpanI Jayantha is completing her PhD on 'Behavioural ecology of the rehabilitated juvenile elephants at the Udawalawa National Park, Sri Lanka' attached to the University of Colombo while serving as the Country Representative of the Born Free Foundation, UK, a wildlife conservation and welfare charity. Her field conservation activies was appreciated by the SAARC Youth Award 2008, on the theme - protecting the environment in South Asia. P.N. DaYAWANSA is a Senior Lecturer in Zoology at the University of Colombo. His lectures cover animal behaviour, ornithology and wildlife conservation. $\mathrm{He}$ has been conducting several field surveys on biodiversity of Sri Lanka attached to the university.

U.K.G.K. PADMALAL is a Senior Lecturer in Zoology at the Open University of Sri Lanka. Many graduate and undergraduate stdents are into research on environmental studies under his guidance attached to the Open University. He's a well known elephant biologist and a research advisor at the Department of Wildlife Conservation, Sri Lanka.

W.D. RatnasooriYa is the Senior Professor in Zoology at the University of Colombo. He was awarded his D.Sc. in Physiology from the University of Peradeniya. His other research areas include mammalian biology (particularly elephants), pharmacology and toxicology. He's been a recepient of several research awards for many years. 